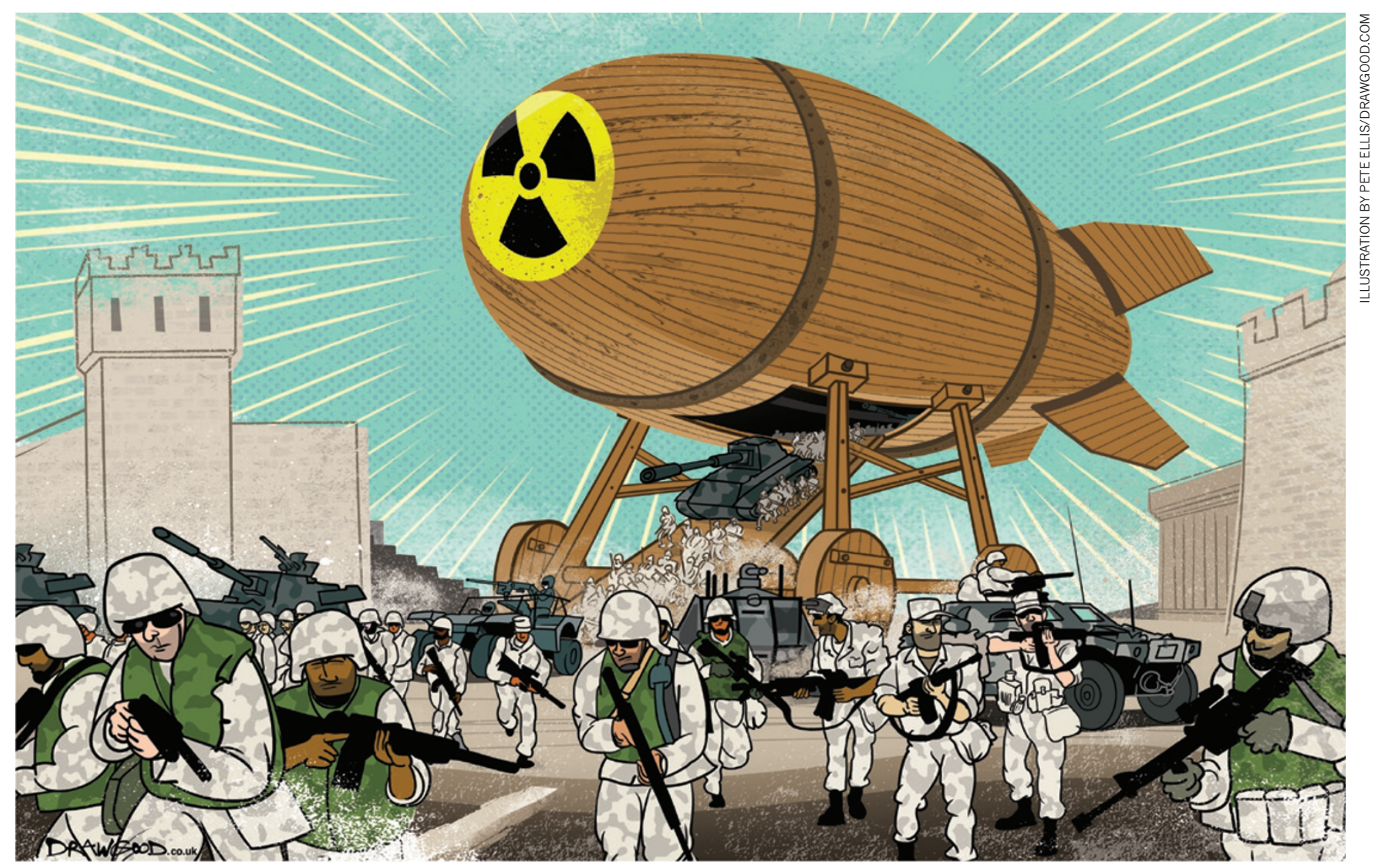

\title{
A call for global nuclear disarmament
}

\section{Danger from nuclear weapons is mounting. It is time to take control of the nuclear fuel cycle and move towards a world without warheads, says Scott D. Sagan.}

$\mathrm{D}$ eclassified documents have revealed that the 1962 Cuban missile crisis was far more dangerous than anyone knew at the time. An American U-2 spy plane accidentally flew into Soviet airspace and US fighter jets armed with nuclear-tipped missiles entered the Bering Strait to rescue it. US Minuteman missile controllers jury-rigged their systems so that they could launch the nuclear missiles on their own if necessary. Pentagon planners began preparing for the possible invasion of Cuba, totally unaware that Soviet tactical nuclear weapons were already deployed on the island and that local commanders had the authority to use them ${ }^{1}$. US President John F. Kennedy and Soviet Premier Nikita Khrushchev avoided nuclear war in October 1962, but we now know how close they came to disaster ${ }^{2}$ (see page 27).
Fifty years on, we live in a nuclear world that has not just two superpowers but nine nuclear-weapons states, with new ones looming on the horizon (see 'World of weapons'). The governments of these emergent nuclear states may not make the same mistakes that Russia and the United States made during the cold war, but they will make others.

We have entered a grave new world where governments believe that shielding themselves with their nuclear weapons will allow them to engage more safely in aggressive action, and increase nuclear proliferation by selling their technology to other governments. And it is a world where nuclear materials and weapons are becoming

\section{$\rightarrow$ NATURE.COM}

More on scientific steps to nuclear

disarmament:

go.nature.com/sxcyne increasingly vulnerable to theft and use by terrorists.

Looking at this prospect, some politicians and analysts have optimistically argued that new nuclear powers will behave cautiously and that a stable form of global nuclear deterrence is likely. For example, in 2007 Jacques Chirac, then president of France, told the press that it "would not be very dangerous" if Iran obtained nuclear weapons. If Iranian leaders ever used the bomb, he argued, Tehran would be destroyed immediately in retaliation ${ }^{3}$. Others are more pessimistic and insist that the only way to counter nuclear proliferators such as Iran is through preventive military operations. But such attacks are unlikely to be completely effective, could trigger wider wars and, over the long term, could actually 
encourage the spread of nuclear weapons.

Neither passivity nor preventive war are likely to lead to a safer nuclear future. Given the gravity of the risks we face, careful and steady movement towards global nuclear disarmament should be our goal. The complex and global nature of emerging nuclear dangers will require complex and global solutions. Scientists, engineers and governments must work together to improve verification of nuclear disarmament and to strengthen international control of uranium enrichment and plutonium reprocessing technologies.

\section{EMERGING DANGERS}

The dangers of the emerging nuclear landscape can be seen clearly in Pakistan. Within months of testing its first nuclear weapon in May 1998, the Pakistani military sent soldiers disguised as mujahedin guerillas into Indian-held Kashmir, a move that sparked the 1999 Kargil War and led to a series of nuclear threats between New Delhi and Islamabad. Pakistani nuclear scientist Abdul Qadeer Khan then established an infamous network that sold centrifuge technology to Iran, North Korea and Libya. Pakistan also highlights the risks of nuclear terrorism: the army is fighting internal Pakistani Taliban threats and has been penetrated by Islamist radical insiders ${ }^{4}$.

Islamabad is aware of these dangers and has strengthened security measures, some with US assistance, including steps to ensure the reliability of its personnel and to protect its nuclear arsenal from terrorists while the weapons are stored in bunkers at military bases ${ }^{5}$. Yet a dangerous 'vulnerabilityinvulnerability paradox' remains. In a future crisis with India, the Pakistani military is likely to place its nuclear arsenal on alert, mating the warheads with mobile missile launchers and moving the missiles outside its bases and into field positions. This operation would make Pakistan less vulnerable to attack by India, but make the weapons far more vulnerable to seizure by terrorists.

Similar nuclear dangers can be seen in Iraq, which tried and failed to develop the bomb. We now know, from documents captured after the fall of Baghdad in 2003, that Saddam Hussein abandoned his secret nuclear-weapons-development programme after UN inspectors discovered it in the wake of the first Gulf War. But we can learn important lessons about how new nuclearweapons states might act by studying how Saddam envisioned using nuclear weapons as a shield for aggression towards other nations.

The captured documents reveal that before the invasion of Kuwait in 1990, Saddam predicted that Iraq would have nuclear weapons within five years. He asked his colleagues, rhetorically, "If the Arabs were to have a nuclear bomb, wouldn't they take the territories that were occupied after 1967?" In the late 1970s, Saddam told Iraqi leaders that owning nuclear weapons would permit Iraq to launch a conventional war against Israel without the fear that Tel Aviv would, in desperation, retaliate with its nuclear arsenal. The transcript of Saddam's secret speech is chilling: "We can guarantee the long war that is destructive to our enemy, and take at our leisure each metre of land and drown the enemy with rivers of blood."7 The world is fortunate that Saddam was forced to destroy his nuclear programme after the 1991 Gulf War.

North Korea poses a serious nuclear threat. Its government has behaved aggressively since conducting its first nuclear test in 2006, and a second in 2009. In 2010, it was accused of sinking a South Korean Navy vessel, the Cheonan, which killed 46 seamen. North Korean artillery shelled the South Korean island of Yeonpyeong in November that year, killing two marines and two civilians. In addition, North Korea is such an economic basket case that it seems willing to sell almost anything: from counterfeit currency, fake pharmaceuticals and illicit drugs to the more lucrative business of smuggling missile and nuclear technology. North Korean leaders may not sell actual nuclear bombs to other countries - they have only enough nuclear material for a handful of weapons for their own country's use - but they have shipped missiles without nuclear warheads to Pakistan and Iran. They were also caught secretly selling uranium hexafluoride (used to make nuclear reactor fuel, or a bomb) to Libya in 2004 and a plutonium production reactor to Syria in 2007.

\section{IRAN'S NUCLEAR SHIELD}

Why should we worry about a nuclear Iran? The gravest danger is not that leaders in Tehran will order a suicidal nuclear first strike on Israel or the United States. The real danger is that if Iran acquires nuclear weapons, leaders in Tehran will see them as a shield behind which they can engage in conventional and terrorist aggression.

Iran is already a major arms supplier to Hezbollah, the Lebanon-based Shi'a militia, and supports its attacks against civilian and military targets inside Israel and other Middle Eastern countries. Iran also covertly armed Iraqi Shi'a militia fighting US troops in Iraq. Moreover, the Islamic Revolutionary Guard Corps - responsible for running Iran's operations in support of terrorist organizations - controls the nuclear programme. To have nuclear command and terrorist ties within the same organization is a deadly mix. Saudi officials have declared that if Iran gets the bomb, they too will develop a nuclear arsenal, which would add one more to the list of dangerous new nuclear states.

Given how far Iran has already gone with its nuclear programme, some politicians and analysts advocate air strikes - or even a preventive war - against the country. An attack, however, would have serious global economic costs, cause many Iranian civilian casualties and would be unlikely to solve the problem. Preventive attacks can invigorate rather than destroy a covert nuclear-weapons programme. We learned this in 1981, when Israeli jet fighters bombed Iraq's only nuclear reactor, and Saddam then started a betterfunded and more covert nuclear-weapons

\begin{tabular}{|c|c|}
\hline $\begin{array}{l}\text { "The choice } \\
\text { is between }\end{array}$ & $\begin{array}{l}\text { on secret uranium- } \\
\text { enrichment facilities }^{8} \text {. }\end{array}$ \\
\hline . & Fortunately, we are \\
\hline nuclear & not yet at the crisis \\
\hline & point when the only \\
\hline e with many & options are to attack \\
\hline pre nuclear & $\begin{array}{l}\text { Iran or live with a } \\
\text { nuclear-armed Iran. } \\
\text { The global policy }\end{array}$ \\
\hline
\end{tabular}
objective should be to push the day of reckoning over the distant horizon. We must create time for sanctions and cyber-sabotage to delay Iran's progress, raise the costs of its unwillingness to constrain its enrichment programme, and enable diplomatic initiatives to be effective. A potential negotiated settlement could include agreement for regular international inspections but allow Iran to keep the Natanz uranium-enrichment centre and a store of low-enriched uranium. This would not be ideal because it would leave Iran with a long-term nuclear break-out option. But it would be better than a preventive attack or blind faith in nuclear deterrence.

Nuclear weapons may have been a dangerous necessity to ensure the cold war stayed cold. But scholars and policy-makers who are nostalgic for the brutal simplicity of that era's nuclear deterrence do not understand how much the world has changed. The choice we face today is not between a nuclear-weapons-free world or a return to bipolar cold war deterrence, but between a world free of nuclear weapons or one with many more nuclear states.

\section{ROAD TO DISARMAMENT}

The technical and political challenges that confront proponents of nuclear disarmament are complex and serious. We lack adequate disarmament-verification technology, such as techniques to permit remote sensing of covert weapons-related activities. Some allies rely on extended nuclear security guarantees - US commitments to retaliate with nuclear weapons if the ally is attacked. And increasing numbers of countries are both developing nuclear power and demanding the right to build uranium enrichment and plutonium reprocessing facilities, which could be used for peaceful or nefarious purposes. It is by no means clear that the United States and 


\section{WORLD OF WEAPONS}

Since the start of the cold war, the number of nuclear states has risen to nine, adding to regional tensions.
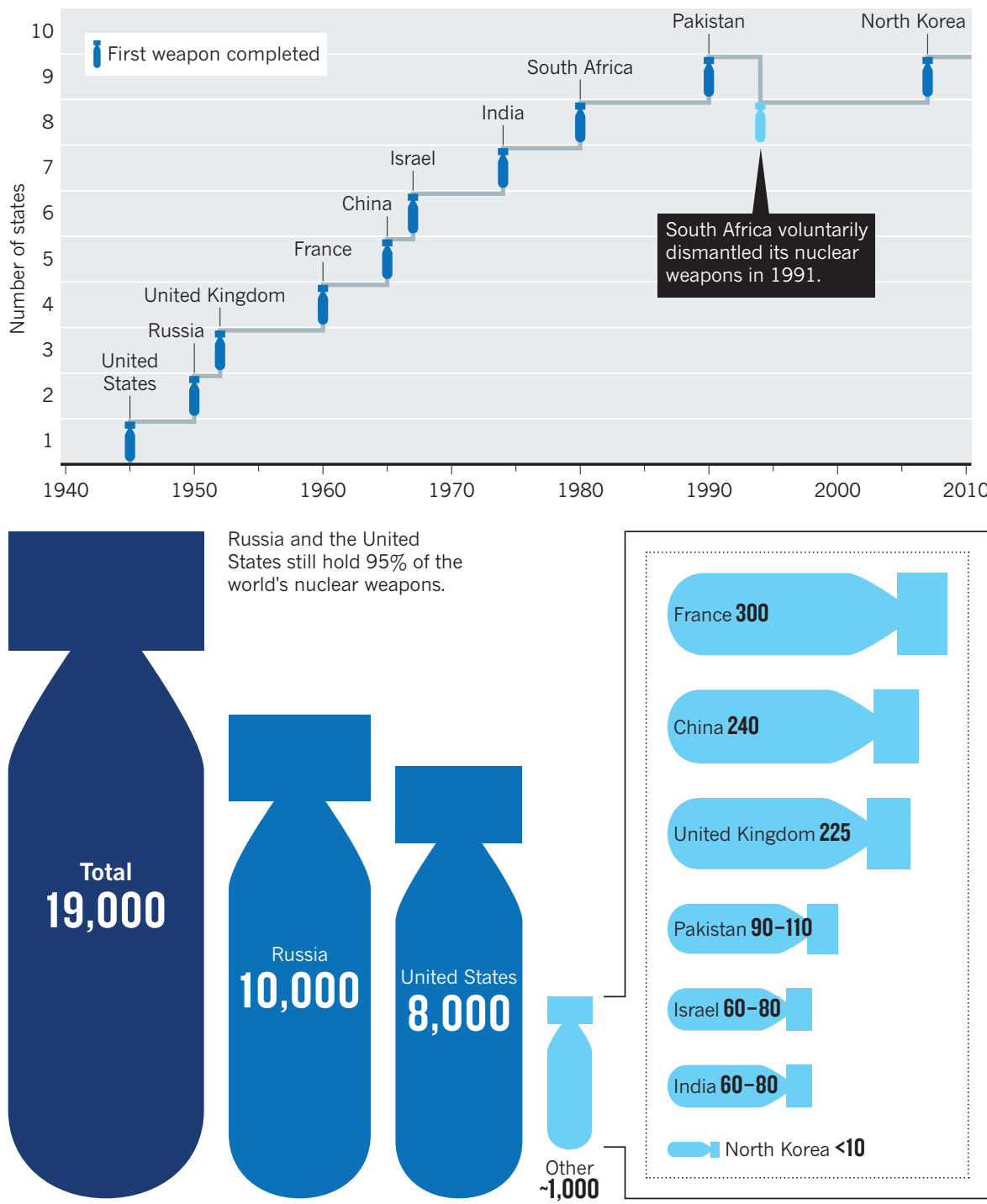

Russia and the United States still hold $95 \%$ of the world's nuclear weapons.
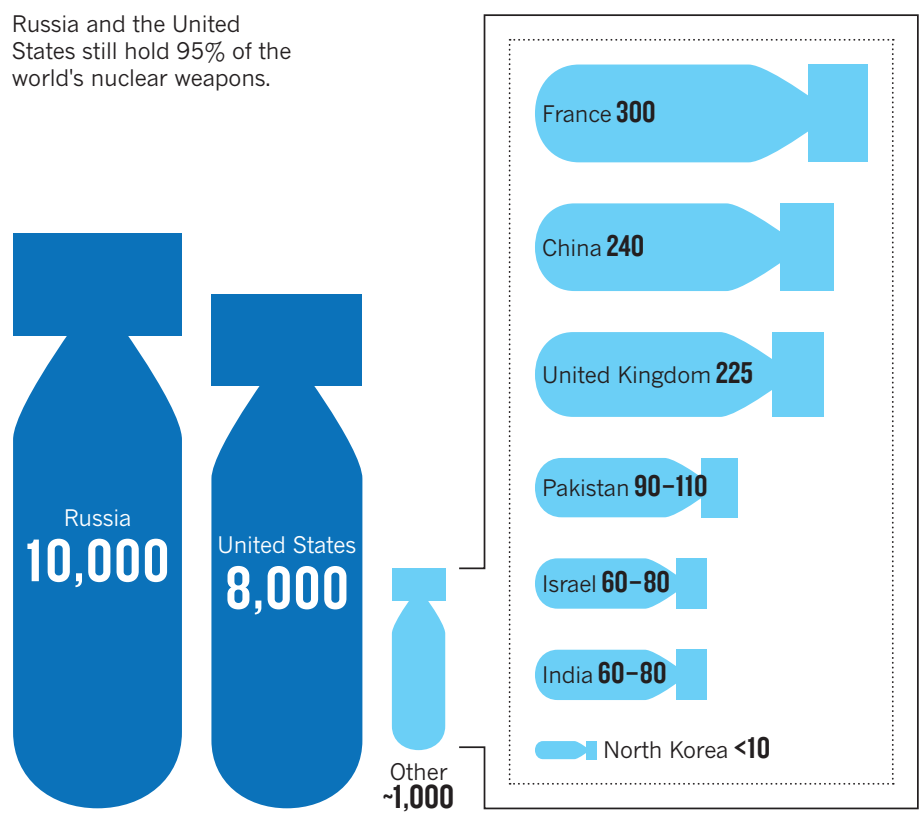

other nuclear-weapons states will overcome these challenges any time soon. What is clear is that existing nuclear-weapons states cannot disarm without the partnership of non-nuclear-weapons states ${ }^{9}$.

President Barack Obama, unlike previous US presidents, has correctly noted that the nation's membership in the NonProliferation Treaty (NPT) commits it to working towards nuclear disarmament ${ }^{10}$. By taking its NPT obligations seriously, his administration's 2010 Nuclear Posture Review argued, "we strengthen our ability to mobilize broad international support for the measures needed to reinforce the nonproliferation regime and secure nuclear materials worldwide"11. At the successful 2010 NPT Review Conference, most non-aligned countries praised the New START (Strategic Arms Reduction Treaty) US-Russian arms-control agreement, and supported the creation of nuclear-power inspection protocols. This shows that

progress on disarmament aids success in non-proliferation ${ }^{12}$.

It will be more difficult to achieve disarmament if there are many 'latent nuclearweapons states' with their own uranium enrichment or plutonium reprocessing facilities that could produce fuel for nuclear power or weapons. It is imperative that governments work together to establish international control of such enrichment and reprocessing technologies - although they are used to produce nuclear fuel for power reactors, they could also be misused to build nuclear bombs. All such facilities should, in the future, be managed by an international agency and built under permanent safeguard agreements that ensure that if any country were to withdraw from the NPT, it could not then legally use the facility for a nuclearweapons programme.

There are many important tasks for scientists and engineers on what will be, at best, a long and winding road towards nuclear disarmament. We will need advanced verification technologies that can detect covert weapons-related activities remotely. As states move down the disarmament path, improved stockpile-stewardship programmes will be needed to ensure that nuclear arsenals remain reliable as they shrink, without the need for nuclear testing. We will also need to design advanced nuclear reactors that can produce energy for civilian purposes, but with less risk that this will lead to weapons proliferation or theft of nuclear materials by terrorists.

A nuclear-weapons-free world will not be a world without conflicts of interest or war. Nor will it be a utopia in which governments never feel tempted to cheat on their global obligations. Indeed, the maintenance of 'global zero' would require that conventionally armed major powers be prepared to enforce nuclear disarmament and nonproliferation commitments in a fair and vigorous manner. Potential proliferators may have to be 'forced' to comply.

The strategic challenges we face are daunting and we may end up with small nuclear arsenals rather than attain the global-zero landmark. But even that would be a much safer world than the one we live in now. If we fail to work together to achieve nuclear disarmament, the world we are heading towards - bristling with nuclear-weapons states, with more nuclear weapons, and the ever-present threat of nuclear terrorism - is even more

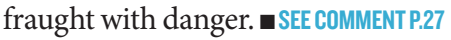

Scott D. Sagan is the Caroline S. G. Munro professor of political science and a senior fellow at the Center for International Security and Cooperation, Stanford University, California 94305, USA. e-mail:ssagan@stanford.edu

1. Dobbs, M. One Minute to Midnight 191-192, 258, 276-279 (Knopf, 2008).

2. Sagan, S. D. The Limits of Safety 81-91 (Princeton Univ. Press, 1993)

3. Sciolino, E. \& Bennhold, K. Chirac strays from assailing a nuclear Iran. The New York Times (1 February 2007).

4. Lister, T. \& Kassim, A. Arrest of Pakistani officer revives fears of extremism within military. CNN World (22 June 2011)

5. Sanger, D. E. The Inheritance: The World Obama Confronts and the Challenges to American Power 220-224 (Harmony, 2009).

6. Brands, H. \& Palkki, D. Int. Security 36, 133-166 (2011).

7. Palkki, D. Stout, M. E. \& Woods, K. M. The Saddam Tapes 223-224 (Cambridge Univ. Press, 2011).

8. Braut-Hegghammer, M. Int. Security 36, 101-132 (2011).

9. Sagan, S. D. Shared Responsibilities for Nuclear Disarmament: A Global Debate. AAAS Occasional Paper, 1-13 (AAAS; 2010).

10.Miller, S. E. et al. Nuclear Collisions: Discord, Reform \& the Nuclear Nonproliferation Regime. AAAS Occasional Paper, 1-41 (AAAS; 2012).

11. Nuclear Posture Review Report (US Dept. of Defense, 2011); available at www.defense.gov/npr.

12. Müller, H. The Nonproliferation Review 18, 219-236 (2011). 